\title{
THE CARBON DIOXIDE REQUIREMENTS OF ANAEROBIC BACTERIA
}

\author{
SHEENA REILLY* \\ Department of Medical Microbiology and Public Health Laboratory, Luton and Dunstable \\ Hospital, Lewsey Road, Luton LU4 ODZ
}

\section{Plate XXXIX}

FOR ALMOST a century, experimental evidence concerning the importance of carbon dioxide for bacterial growth has been accumulating (Winogradsky, 1890; Rockwell, 1923; Rockwell and Highberger, 1927; Valley and Rettger, 1927; Valley, 1928; Gladstone, Fildes and Richardson, 1935; Wimpenny, 1969). The attention of early workers was directed primarily at aerobes such as Neisseria gonorrhoeae (Chapin, 1918), N. meningitidis (Cohen and Fleming, 1918), Brucella abortus (Smith, 1924; Wilson, 1931) and Mycobacterium tuberculosis (Wherry and Ervin, 1918; Davies, 1940). With the recent resurgence of interest in anaerobic bacteriology, the essential or stimulatory effect of $\mathrm{CO}_{2}$ on the growth of obligate anaerobes has become widely recognised. Current anaerobic culture techniques commonly employ $5-10 \% \mathrm{CO}_{2}$ in the incubation atmosphere to achieve optimal growth (Watt, 1973; Stalons, Thornsberry and Dowell, 1974; Willis, 1977). Nevertheless, there is a lack of precise information relating to the quantitative $\mathrm{CO}_{2}$ requirements of many clinically important anaerobic bacteria. Preliminary experiments in this laboratory revealed a wide variation in the $\mathrm{CO}_{2}$ requirements of different species of anaerobic bacteria; the observation that relatively low concentrations of $\mathrm{CO}_{2}$ were adequate for satisfactory growth of certain anaerobes was of particular interest. The present study reports the effect of different concentrations of $\mathrm{CO}_{2}$ on the growth of a range of anaerobic bacteria isolated from clinical sources.

\section{MATERIALS AND METHODS}

Micro-organisms. The following organisms were examined: 57 strains of Bacteroides spp. isolated from faeces, comprising $B$. fragilis (20 strains), B. vulgatus ( 5 strains), B. distasonis (10 strains) and $B$. thetaiotaomicron (22 strains); 30 strains of $B$. melaninogenicus freshly isolated from the upper respiratory tract; 11 strains of Fusobacterium spp., comprising F. varium (6 strains), $F$. necrophorum ( 3 strains) and one strain each of $F$. necrogenes and $F$. gonidiaformans; 23 strains of Clostridium perfringens; 19 strains of $C$. difficile; 4 strains of $C$. innocuum; 2 strains of $C$. bifermentans; one strain each of $C$. chauvoei, $C$. histolyticum, $C$. sporogenes and $C$. septicum; 14 strains of Bifidobacterium spp.; 12 strains of anaerobic cocci, comprising Peptococcus asaccharolyticus (7 strains), P. magnus (1 strain), P. prevoti (1 strain), Peptostreptococcus anaerobius ( 2 strains) and Pst. micros (1 strain). Identification of isolates was by the methods of Holdeman, Cato and Moore (1977).

Received 5 Mar. 1980; Accepted 27 Mar. 1980

* Present address: Public Health Laboratory, General Hospital, Greenbank Road, Plymouth PL4 8NN. 
Culture medium. Blood-agar Plates No. 2 (LAB-M Ltd, Salford, Lancs) containing 7\% horse blood were used.

Inoculation of medium. Suspensions of each organism were prepared in sterile saline. The approximate concentrations of cells were as follows: Bacteroides spp. and Fusobacterium spp., $10^{5} / \mathrm{ml} ;$ B. melaninogenicus, $10^{6} / \mathrm{ml}$; Clostridium spp., $10^{7} / \mathrm{ml} ;$ Bifidobacterium spp. and anaerobic cocci, $10^{8} / \mathrm{ml}$. A multipoint inoculator was used to seed blood-agar plates with $0.001 \mathrm{ml}$ of each suspension. A 9-cm petri dish conveniently accommodated 20 cultures.

Atmospheric conditions. Standard Baird and Tatlock 3-litre jars, equipped with Schraeder valves, were fitted with $4 \mathrm{~g}$ of freshly activated palladium catalyst before each experiment. Pure $\mathrm{CO}_{2}$ and $\mathrm{H}_{2}$ were obtained from separate cylinders supplied by the British Oxygen Company. Each jar was evacuated to an internal pressure of $40 \mathrm{~mm} \mathrm{Hg}$, i.e., $720 \mathrm{~mm} \mathrm{Hg}$ below atmospheric pressure; residual $\mathrm{CO}_{2}$ in the atmosphere was considered to be negligible. The appropriate volume of $\mathrm{CO}_{2}$ was introduced from a balloon. Accurate measurement of small volumes of $\mathrm{CO}_{2}$ was achieved by drawing the gas into a graduated syringe and injecting it into the side arm of the anaerobic jar. Volumes of $\mathrm{CO}_{2}$ in excess of $10 \%$ were admitted via the Schraeder valve and monitored manometrically, care being taken to flush through all connecting tubing with $\mathrm{CO}_{2}$. Internal and external pressures were then equilibrated by the introduction of pure $\mathrm{H}_{2}$. The following concentrations of $\mathrm{CO}_{2}$ by volume were chosen: $0 \cdot 25 \%, 0 \cdot 5 \%, 0 \cdot 75 \%, 1 \%, 2 \%, 5 \%, 10 \%$, $20 \%, 40 \%, 60 \%$ and $80 \%$. For comparative purposes, cultures were incubated in parallel in the anaerobic atmosphere currently in use in the routine clinical laboratory, which was $7 \% \mathrm{CO}_{2}$ in $\mathrm{H}_{2}$.

Three additional atmospheres were provided to give information on the effect of elimination of $\mathrm{CO}_{2}$ on bacterial growth: one jar was evacuated and then filled with pure $\mathrm{H}_{2}$; an open petri dish containing $2 \mathrm{ml}$ of $1 \mathrm{~N} \mathrm{NaOH}$ solution was placed inside a similar jar filled with $\mathrm{H}_{2}$. Any difference in growth between these two atmospheres was attributed to the absorption by $\mathrm{NaOH}$ of residual $\mathrm{CO}_{2}$ not eliminated by the evacuation-replacement procedure and of $\mathrm{CO}_{2}$ evolved during bacterial metabolism. Because preliminary experiments demonstrated enhancement of growth in the presence of $0.25 \% \mathrm{CO}_{2}$, a third jar was included containing this concentration of $\mathrm{CO}_{2}$ plus $2 \mathrm{ml}$ of $1 \mathrm{~N} \mathrm{NaOH}$ and it was incubated in parallel with a jar containing $0.25 \% \mathrm{CO}_{2}$ but devoid of $\mathrm{NaOH}$, to verify the efficacy of $\mathrm{NaOH}$ in removing exogenously supplied and endogenously produced $\mathrm{CO}_{2}$.

All cultures were incubated at $37^{\circ} \mathrm{C}$ for $48 \mathrm{~h}$ with the exception of those for B. melaninogenicus which remained undisturbed for $72 \mathrm{~h}$.

Assessment of growth. Bacterial growth in each atmosphere was compared in terms of numbers of colonies and individual colony size; in addition, variations in haemolysis, pigmentation and fluorescence were noted when applicable.

\section{RESULTS}

The results obtained are summarised in fig. 1 .

Bacteroides spp. (excluding B. melaninogenicus). No strain grew in atmospheres from which $\mathrm{CO}_{2}$ had been totally removed by the inclusion of $\mathrm{NaOH}$, but scanty growth of a few strains was evident in the gaseous environment in which the $\mathrm{CO}_{2}$ concentration was considered negligible by the evacuationreplacement procedure. Supplementation of the atmosphere with $0.25 \% \mathrm{CO}_{2}$ resulted in good growth of all strains; this was not further improved by incubation in concentrations of $\mathrm{CO}_{2}$ up to $40 \%$. Increasing the $\mathrm{CO}_{2}$ concentration above $40 \%$ resulted in considerable inhibition of growth, and in general only strains of $B$. fragilis were consistently capable of growth, albeit impaired, in $80 \% \mathrm{CO}_{2}$.

B. melaninogenicus. No strain grew in the presence of $\mathrm{NaOH}$ or in an atmosphere lacking exogenous $\mathrm{CO}_{2}$. Scanty growth of some strains was just discernible after incubation in $0.25 \% \mathrm{CO}_{2}$ for $72 \mathrm{~h}$; increasing the $\mathrm{CO}_{2}$ content 


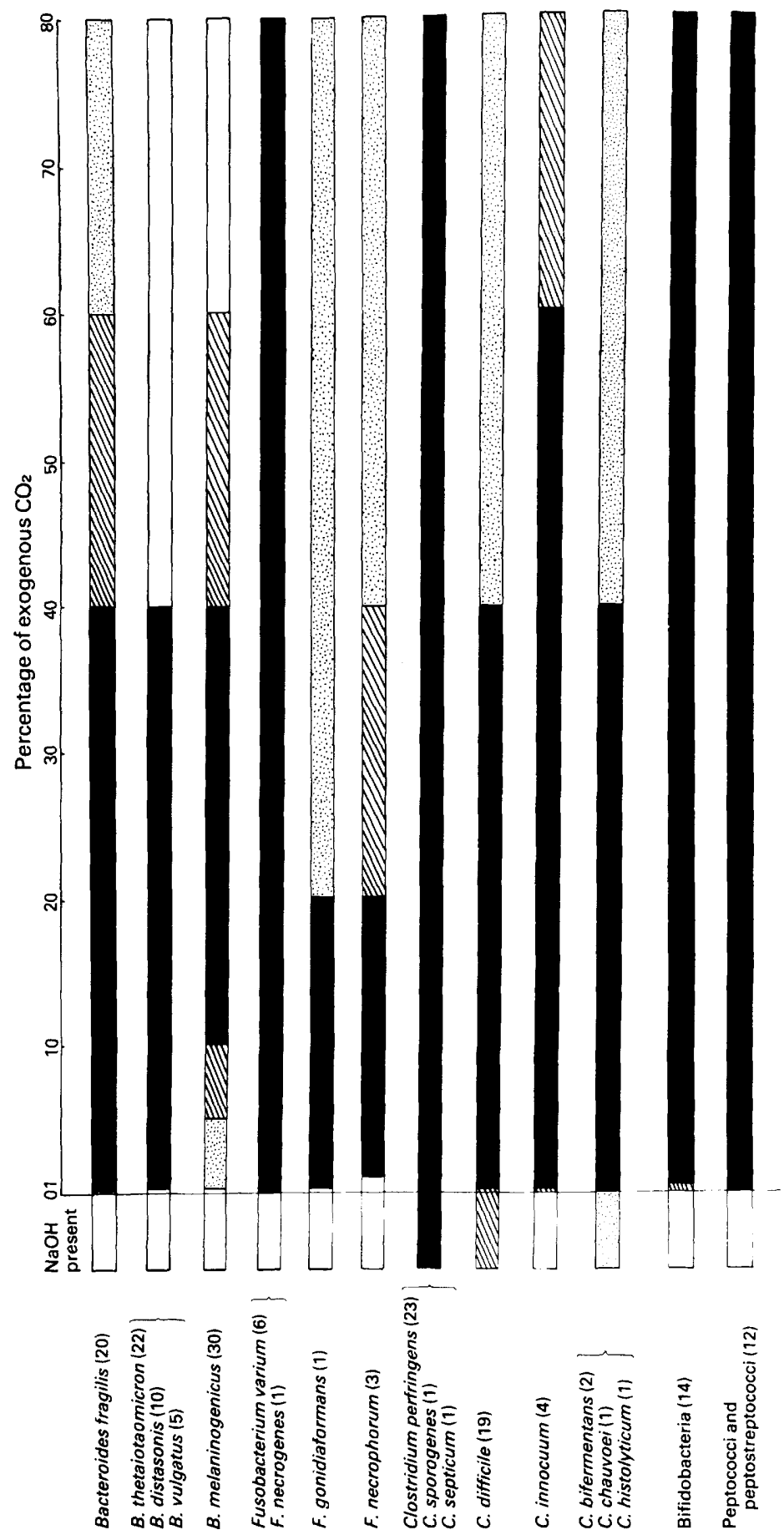

FIG. 1-Growth of anaerobic bacteria in different concentrations of $\mathrm{CO}_{2}$. Figures in parentheses indicate number of strains tested. $\square=$ No growth; $\approx=$ scanty growth; $\mathbf{0}=$ moderate growth; $\boldsymbol{\nabla}=$ good growth. Eight strains of $B$. melaninogenicus failed to grow in $0.25 \% \mathrm{CO}_{2}$, three of which failed to grow in $5 \%$ $\mathrm{CO}_{2}$. 
to $10 \%$ produced consistently good growth of all strains. Incubation of cultures in concentrations of $\mathrm{CO}_{2}$ up to $40 \%$ resulted in further increase in the size of individual colonies and considerable enhancement of haemolysis (figs. 2-5). Atmospheres containing $60 \% \mathrm{CO}_{2}$ were inhibitory to many strains of $B$. melaninogenicus, colonies being smaller, more deeply pigmented and with reduced zones of haemolysis. The characteristic brick-red fluorescence of this species under a Wood's lamp was apparently unaffected by the variations in atmospheric $\mathrm{CO}_{2}$ content.

Fusobacterium spp. Absorption of $\mathrm{CO}_{2}$ by $\mathrm{NaOH}$ inhibited growth of all strains of fusobacteria. Only $F$. varium and $F$. necrogenes were capable of growth in an atmosphere of $\mathrm{H}_{2}$ unsupplemented with $\mathrm{CO}_{2}$. Increased concentrations of $\mathrm{CO}_{2}$ did not appear to stimulate these species and growth was unimpaired by $80 \% \mathrm{CO}_{2}$. In contrast, $F$. necrophorum required at least $1 \%$ $\mathrm{CO}_{2}$ for growth, and the tolerance of this species to $\mathrm{CO}_{2}$ declined in atmospheres containing $>20 \% \mathrm{CO}_{2}$. Good growth of the single strain of $F$. gonidiaformans occurred in the range $0.25 \%-20 \% \mathrm{CO}_{2}$.

$C$. perfringens. All strains examined grew equally well in the presence or absence of $\mathrm{CO}_{2}$. Enhancement of growth was not produced by increasing concentrations of $\mathrm{CO}_{2}$, but haemolysis due to $\alpha$-toxin was progressively intensified.

C. difficile and $C$. innocuum. If $\mathrm{CO}_{2}$ was absorbed from the atmosphere, growth of $C$. difficile was moderate, but the colonies were small and irregular. Recovery of $C$. innocuum was not achieved in the presence of $\mathrm{NaOH}$. Both species exhibited moderate growth in an atmosphere of $\mathrm{H}_{2}$ devoid of exogenously supplied $\mathrm{CO}_{2}$, but were enhanced by the addition of $0.25 \% \mathrm{CO}_{2}$; further supplementation did not improve growth. Indeed, $C$. difficile grew poorly in exogenous $\mathrm{CO}_{2}$ concentrations in excess of $40 \%$. Moderate growth of $C$. innocuum persisted in the presence of $80 \% \mathrm{CO}_{2}$.

C. bifermentans, $C$. chauvoei and C. histolyticum. Absorption of $\mathrm{CO}_{2}$ resulted in considerable impairment of growth. All species grew well in the presence of $\mathrm{H}_{2}$ without additional $\mathrm{CO}_{2}$ and growth was not improved by increasing the concentrations of $\mathrm{CO}_{2}$. Atmospheres containing $>40 \% \mathrm{CO}_{2}$ caused markea growth inhibition of all species.

$C$. sporogenes and C. septicum. Growth of these two species was unaffected by absorption of atmospheric $\mathrm{CO}_{2}$ and by high $\mathrm{CO}_{2}$ concentrations.

Bifidobacterium spp. With one exception, all 14 strains of bifidobacteria grew well in an atmosphere of $\mathrm{H}_{2}$ without supplementary $\mathrm{CO}_{2}$; none grew in the presence of $\mathrm{NaOH}$. Slightly improved growth followed the addition of $0.5 \%$ $\mathrm{CO}_{2}$ to the atmosphere of the jars. Luxuriant growth occurred in all higher concentrations of $\mathrm{CO}_{2}$ and was not diminished in $80 \% \mathrm{CO}_{2}$.

Anaerobic cocci. Absorption of atmospheric $\mathrm{CO}_{2}$ permitted only scanty growth of a few strains, but all grew well in $\mathrm{H}_{2}$ devoid of exogenous $\mathrm{CO}_{2}$ and were unaffected by further increases in $\mathrm{CO}_{2}$.

\section{Discussion}

One of the requirements for the isolation and identification of anaerobic 
Carbon dioxide ReQUiREMENTS OF ANAEROBES

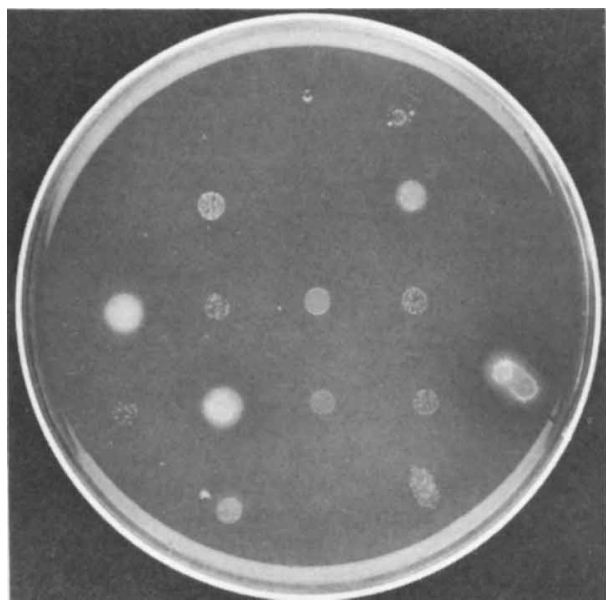

FIG. 2.--Blood-agar plate inoculated with 20 strains of $B$. melaninogenicus, after 72 hours' incubation in $0.25 \% \mathrm{CO}_{2}+\mathrm{H}_{2}$. Note absence of some strains, scanty growth of others and weak haemolysis.

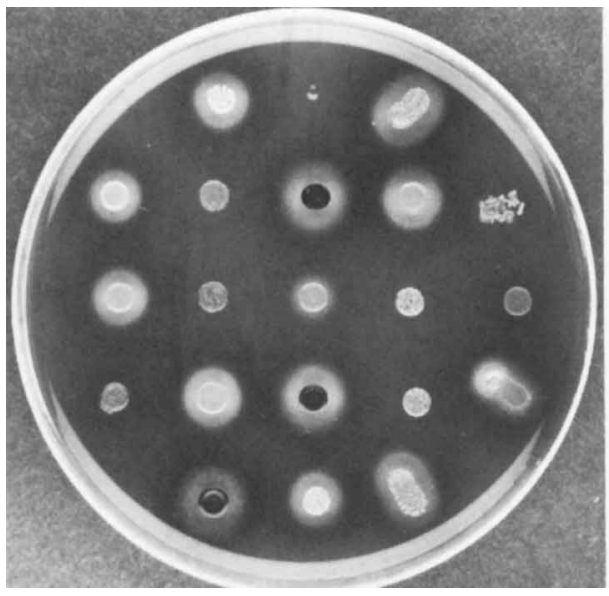

FIG. 4.-Identical strains of $B$. melaninogenicus after 72 hours' incubation in $7 \% \mathrm{CO}_{2}+\mathrm{H}_{2}$. Note good growth of all strains, improved haemolysis and pigmentation of some strains.

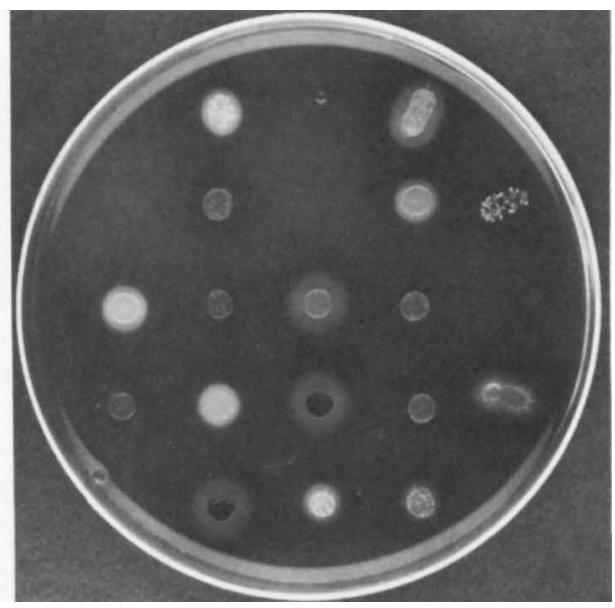

FIG. 3.-Identical strains of B. melaninogenicus after 72 hours' incubation in $5 \% \mathrm{CO}_{2}+\mathrm{H}_{2}$. Note improved growth of some strains, absence of others and enhanced haemolysis.

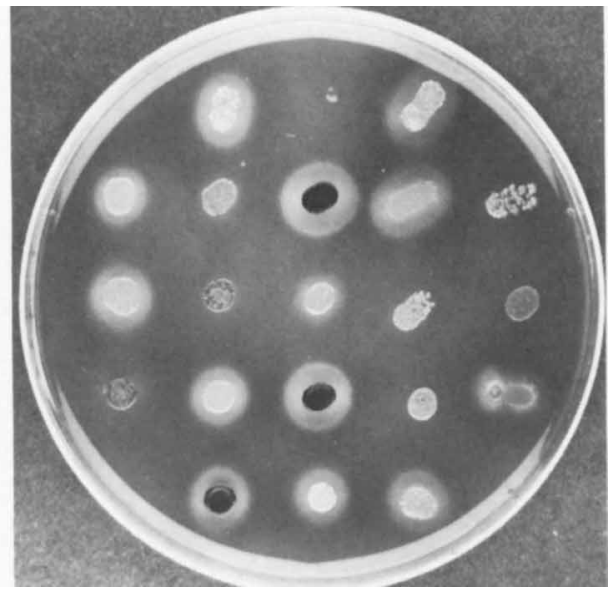

FIG. 5.-Identical strains of B. melaninogenicus after 72 hours' incubation in $10-40 \% \mathrm{CO}_{2}+\mathrm{H}_{2}$. Note optimal growth of all strains and large zones of haemolysis. 
bacteria in the routine clinical laboratory is the presence of an optimal atmosphere. This is of particular importance for fastidious species such as $B$. melaninogenicus, which may be isolated from most ecological sites in the human body after prolonged incubation of clinical specimens. Watt (1973) reported optimal isolation of gram-negative anaerobes and of $C$. tetani and $C$. oedematiens types $\mathrm{A}$ and $\mathrm{B}$, after incubation in $10 \% \mathrm{CO}_{2}$, and it has since become generally accepted that $5-10 \% \mathrm{CO}_{2}$ is a suitable concentration for satisfactory isolation of the majority of anaerobic bacteria.

In this study, the $\mathrm{CO}_{2}$ requirements of an extended range of clinically significant anaerobic bacteria have been critically examined. It is appreciated that in any such examination, the results will be influenced by several factors, for example, the age of the cultures, the type of medium, the inoculum size, the duration of incubation, and $p \mathrm{H}$ changes in the medium. No attempt was made to investigate the latter variable in this work. Agar containing horse blood $7 \%$ $(\mathrm{v} / \mathrm{v})$ was used throughout to facilitate comparisons with routine isolation techniques.

The results confirm the wide range in the $\mathrm{CO}_{2}$ requirements of anaerobic bacteria. A spectrum of $\mathrm{CO}_{2}$ requirements was demonstrated, ranging from $C$. perfringens, $C$. sporogenes and $C$. septicum, the growth of which was apparently unaffected by the concentration of $\mathrm{CO}_{2}$ in the atmosphere, to $B$. melaninogenicus which required $10-40 \% \mathrm{CO}_{2}$ for optimal growth. In accordance with preliminary observations, supplementation of the atmosphere with $0.25 \% \mathrm{CO}_{2}$, the lowest concentration achievable with accuracy, was found to satisfy the $\mathrm{CO}_{2}$ requirements of most of the anaerobes studied, B. melaninogenicus being the notable exception. This growth-stimulating effect was abolished by including $\mathrm{NaOH}$ in identical jars supplied with $0.25 \% \mathrm{CO}_{2}$ and incubated in parallel. It is interesting that many other species of anaerobic bacteria were, however, capable of some growth when the jar was evacuated to an internal pressure of $40 \mathrm{~mm} \mathrm{Hg}$ and the vacuum abolished by replacement with pure $\mathrm{H}_{2}$. This suggests that the residual atmospheric $\mathrm{CO}_{2}$ was utilised by these species.

Anaerobic bacteria exhibited an analogous diversity of response when exposed to high concentrations of $\mathrm{CO}_{2}$. Consistent inhibition of growth was observed when B. thetaiotaomicron, B. vulgatus, B. distasonis, F. necrophorum, $C$. difficile, $C$. bifermentans, $C$. chauvoei and $C$. histolyticum were subjected to exogenous $\mathrm{CO}_{2}$ concentrations exceeding $40 \%$. The quality of growth of all strains of $B$. melaninogenicus was optimal in the presence of $40 \% \mathrm{CO}_{2}$; further increase in the $\mathrm{CO}_{2}$ content resulted in a marked decline in colony size and numbers. In contrast, the strains of $F$. varium, $F$. necrogenes, bifidobacteria and anaerobic cocci continued to grow luxuriantly in all concentrations of $\mathrm{CO}_{2}$ above $40 \%$. As observed by Watt (1973), growth of $C$. perfringens remained unimpaired in $80 \% \mathrm{CO}_{2}$.

$\mathrm{CO}_{2}$ plays an intricate role in bacterial metabolism (Walker, 1932; Ajl and Werkman, 1948; Charles and Roberts, 1968; Wimpenny, 1969). Dehority (1971) demonstrated an absolute requirement for $\mathrm{CO}_{2}$ by those anaerobic rumen bacteria that produce succinic acid as one of their primary end-pro- 
ducts. Many other facultative and obligate anaerobes depend on $\mathrm{CO}_{2}$ for the initiation of growth. From the foregoing results, B. melaninogenicus appears to occupy a unique position among this selection of anaerobic bacteria; an exogenous supply of at least $10 \% \mathrm{CO}_{2}$ is a prerequisite for its successful isolation if incubation is continued for only $72 \mathrm{~h}$. It is well recognised that $B$. melaninogenicus is difficult to maintain in pure culture, and $\mathrm{CO}_{2}$ may be an important factor in the apparent synergism between this species and other anaerobes with which it is commonly associated. The observation that higher concentrations of $\mathrm{CO}_{2}$ (up to $40 \%$ ) may further enhance the colonial appearance of $B$. melaninogenicus could be utilised by the microbiologist with a particular interest in the isolation of these fastidious, slowly growing anaerobes. If the $\mathrm{CO}_{2}$ concentration does not exceed $40 \%$, the isolation of other anaerobic bacteria from clinical specimens would not be appreciably compromised.

It was not intended that this should be an exhaustive study of the $\mathrm{CO}_{2}$ requirements of all anaerobic bacteria, but rather an examination of the influence of varying atmospheric concentrations of $\mathrm{CO}_{2}$ on the growth of a selection of anaerobes of clinical interest. The effect of $\mathrm{CO}_{2}$ on spore germination was not considered. In view of the considerable range of $\mathrm{CO}_{2}$ requirements demonstrated, the current practice of adding $10 \% \mathrm{CO}_{2}$ to the atmosphere of anaerobic jars is to be encouraged; it stimulates optimal growth of all genera of anaerobic bacteria, thus facilitating routine isolation and identification.

\section{SUMMARY}

Some clinically significant anaerobic bacteria were incubated in pure culture in anaerobic jars containing a range of atmospheric concentrations of $\mathrm{CO}_{2}$. Growth of Clostridium perfringens, $C$. sporogenes and $C$. septicum was independent of the amount of $\mathrm{CO}_{2}$. Small supplements of $\mathrm{CO}_{2}(0.25 \%)$ allowed good growth of the majority of anaerobes studied - an observation contrary to established teaching. The exceptions were Fusobacterium necrophorum which showed an absolute requirement for $\mathrm{CO}_{2}$ of at least $1 \%$ and $B$. melaninogenicus which needed an atmospheric content of $10-40 \% \mathrm{CO}_{2}$ for optimal growth. The inclusion of $\mathrm{CO}_{2}$ in the anaerobic jar at a final concentration of $10 \%$ is to be recommended for all routine isolation procedures.

I am indebted to Dr A. T. Willis for his continued interest and encouragement throughout this study, to Mr K. D. Phillips for critical assessment of the work, to Mrs G. Gottobed for her expert technical assistance, Mr J. Harrison for the photography and Mrs M. Senjack for her patience in typing the script.

\section{REFERENCES}

AJl, S. J. AND Werkman, C. H. 1948 Replacement of $\mathrm{CO}_{2}$ in heterotrophic metabolism. Archs Biochem., 19, 483.

Chapin, C. W. 1918. Carbon dioxid in the primary cultivation of the gonococcus. J. infect. Dis., 23, 342. 
Charles, H. P. and Roberts, G. A. 1968. Carbon dioxide as a growth factor for mutants of Escherichia coli. J. gen. Microbiol., 51, 211.

Cohen, M. B. and Fleming, J. S. 1918. The diagnosis of epidemic meningitis and the control of its treatment by rapid bacteriologic and serologic methods. J. infect. Dis., 23, 337.

DAviEs, R. 1940. The effect of carbon dioxide on the growth of the tubercle bacillus. Brit. J. exp. Path., 21, 243.

Dehority, B. A. 1971. Carbon dioxide requirement of various species of rumen bacteria. $J$. Bact., 105, 70.

Gladstone, G. P., Fildes, P. and Richardson, G. M. 1935. Carbon dioxide as an essential factor in the growth of bacteria. Brit. J. exp. Path., 16, 335.

Holdeman, L. V., Cato, E. P. AND MoORE, W. E. C. 1977. Anaerobe laboratory manual, 4th ed. Virginia Polytechnic Institute and State University: Blacksburg.

RockweLl, G. E. 1923. The influence of carbon dioxide on the growth of bacteria. J. infect. Dis., 32, 98.

RoCKWEll, G. E. ANd Highberger, J. H. 1927. The necessity of carbon dioxide for the growth of bacteria, yeasts and molds. J. infect. Dis., 40, 438.

Sмiтн, T. 1924. Some cultural characters of Bacillus abortus (Bang) with special reference to $\mathrm{CO}_{2}$ requirements. J. exp. Med., 40, 219.

Stalons, D. R., Thornsberry, C. And Dowell, V. R. 1974. Effect of culture medium and carbon dioxide concentration on growth of anaerobic bacteria commonly encountered in clinical specimens. Appl. Microbiol., 27, 1098.

VALLEY, G. 1928. The effect of carbon dioxide on bacteria. Quart. Rev. Biol., 3, 209.

VALLEY, G. AND ReTTGER, L. F. 1927. The influence of carbon dioxide on bacteria. J. Bact., $14,101$.

Walker, H. H. 1932. Carbon dioxide as a factor affecting lag in bacterial growth. Science, N.Y., 76, 602 .

WATT, B. 1973. The influence of carbon dioxide on the growth of obligate and facultative anaerobes on solid media. J. med. Microbiol., 6, 307.

Wherry, W. B. AND ERvin, D. M. 1918. The necessity of carbon dioxid for the growth of $B$. tuberculosis. J. infect. Dis., 22, 194.

WiLLIS, A. T. 1977. Anaerobic bacteriology-clinical and laboratory practice, 3rd ed. Butterworths: London, p. 5.

WILSON, G. S. 1931. The gaseous requirements of Br. abortus (bovine type). Brit. J. exp. Path., 12,88 .

WIMPENNY, J. W. T. 1969. Oxygen and carbon dioxide as regulators of microbial growth and metabolism. In Microbial growth, 19th symposium of the Society for General Microbiology, edited by P. M. Meadow and S. J. Pirt. Cambridge University Press: Cambridge, pp. 161-197.

WinOGRadSky, S. 1890. Recherches sur les organismes de la nitrification. Ann. de l'Inst. Pasteur, 4, 257. 